\title{
A Novel Multi Stage Transformer for Compensating Unbalanced Loads
}

\author{
T. AHMADI \\ Engineering faculty, Universidad ECCI, Bogotá, \\ COLOMBIA
}

\begin{abstract}
In the proposed Load balancing transformer, two additional coupling winding are placed in the secondary of each phase. One of these coupling windings is in series with the winding of other phase and this combination of windings is reversely paralleled with the secondary winding of the third phase. Under unbalanced load conditions, the unbalanced part of the load current, flows through the proposed combination of windings. In this way, the unbalanced part of the load current is distributed between all phases. The proposed topology for multi stage load balancing transformer is based on the ordinary load-balancing transformer. Finally, these topologies are simulated with MATLAB and the results are discussed.
\end{abstract}

Key-Words: - Load-balancing, load-balancing transformer, power quality, unbalanced current.

Received: February 1, 2020. Revised: June 18, 2020. Accepted: June 29, 2020. Published: July 15, 2020.

\section{Introduction}

Unbalanced load is a concern in distribution networks. It causes one phase of transformer to reach its rated value earlier, while there is unused capacity in the other phases. This is the reason for increase in manufacturing cost of transformer. Unbalancing in distribution networks also increases the losses in the conductors, brings in losses and produces voltage in the neutral wire, and finally results in voltage drop in the network.

Load balancing is one of the ways to improve power quality. The purpose of this operation can be to increase the load capacity of the power grid, improve the power factor or increase the reliability of the power grid. Due to random behavior of connection and disconnection of single phase loads to the network, and that single phase loads are not uniformly distributed over the network, it is nearly impossible to establish a complete balance in distribution network. However, some techniques have been previously proposed to reduce the unbalancing and its lateral effects. One of them is using of admittance compensative network [1]. Switching the single phase loads on and off, constantly changes the network admittance, so using this method in distribution networks is expensive and impractical. Using the rotating balancers such as synchronous condensers and induction motors to absorb negative component of current, is another approach, which is not economical due to high cost and losses. Using the FACTS controllers is another technique that recently has made prominent progress in theory [3-7]. Using these controllers and dealing with problems such as harmonic capability, efficiency and implementation, relies on advances of technology. Along this, active filters [2], [8], [9] or a combination of FACTS controllers and active filters [10] has been proposed which are expensive, and have complication in design, control and implementation. In [11] a distribution system loss reduction by automatic transformer load balancing is presented. In [12] an overview of the load balancing of electrical power distribution system is prepared. In [13] the losses in three-phase transformers at load balancing is studied. Fuzzy logic ways for load balancing is proposed in [8-10]. In [11-12], other intelligent algorithms like Ant Colony algorithm and heuristic is explained.

In this paper, in addition to evaluation of Loadbalancing transformer, some modifications are 
proposed, so that the ratio of current distribution would be $1 / 2,1 / 2$. These modifications have been applied in order to reduce unbalance and to make complete and effective use of transformer capacity. The proposed Load-balancing transformer can be simply obtained with a little change in the distribution transformer without any need to additional instruments, while it is practical and inexpensive for being implemented in distribution systems.

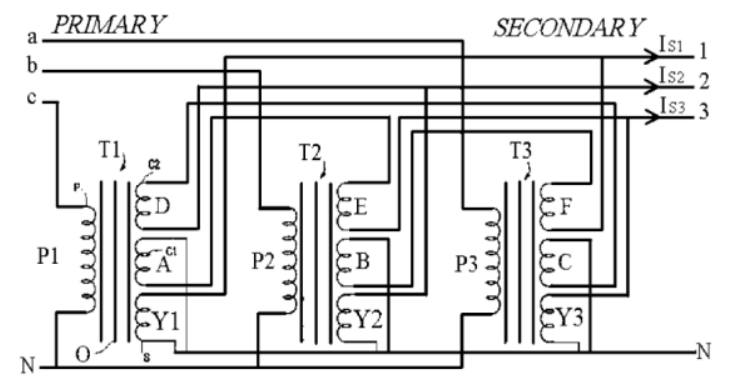

Figure 1. Orginal Load balancing transformer

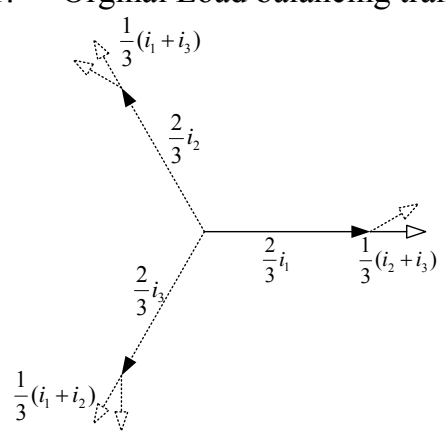

Figure 2. Current distribution in the ordinary load balancing transformer

\section{Analysis of the Load-balancing transformer}

In [11] a particular transformer has been used in order to balance the consumer-side load. In this transformer, the secondary windings are connected together in a special way as shown in Fig. 1.

It is noteworthy that three-phase systems require three different factors with the same magnitude with identical 120 phase differences for each selected to be considered as an acceptable setting for the balanced transformer. To distribute the currents evenly between the three primary phases, a load balancing transformer is presented. It is noteworthy that each secondary phase consists of two parallel branches, as shown in the equivalent circuit of Figure 3, which essentially causes both branches to have the same voltage and phase angle.

The Current distribution in the ordinary loadbalancing transformer is shown in the Fig. 2. This connection is so arranged that one winding of column T1 (A) is in series with a winding of column T2 (E) and finally is paralleled with a winding of column (S3). In this kind of transformer, 2/3 of the load current is obtained by a winding, which is reversely paralleled with a set of two series windings and $1 / 3$ of it supplied by two series windings. For example, according to Fig. 1, 2/3 of the load current for phase 3 of the secondary-side is supplied by winding $S 3$ and $1 / 3$ by two coupling windings $A$ and E. So, the primary-side current of each phase is not equally supplied by three secondary phases according to the equivalent circuit given by Fig. 3 .

\subsection{Transformer primary side current}

Primary side current of each phase of transformer is obtained from vector summation of secondary-side three-phase currents using unequal coefficients. For example, in phase T1 shown in Fig.1, the current iA, is equal to the summation of $-1 / 3\left(i_{2}+i_{3}\right)$ and $2 / 3\left(i_{1}\right)$ this curent unbalance is somehow distribued this current unbalance is somehow distributed among three-phases of the primary-side. This way, amplitude and phase of transformer's primary-side currents can be considerably balanced. Thus, the primary-side currents are introduced as follows:

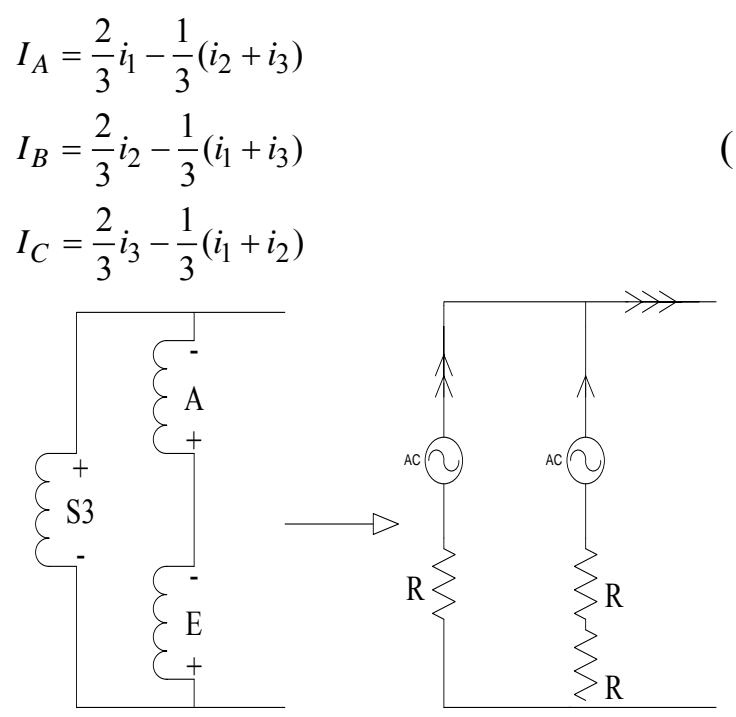

Figure 3. Original load-balancing equivalent circuit for each secondary phase

According to [11], the best condition for the original load-balancing transformer occurs when the current is distributed equally between the two branches. This situation can be achieved if the resistance of each secondary side coupling winding 
is half of that of secondary-side winding. Occurrence of this condition is practically impossible, because to attain no zero sequence voltage on top of the threephase voltages, the number of windings should be identical; this means that resistances of windings have to be identical.

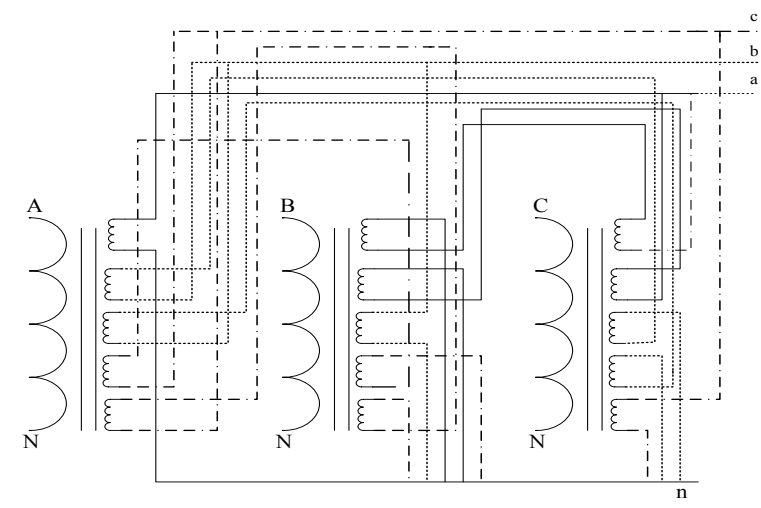

Figure 4. Proposed load-balancing transformer

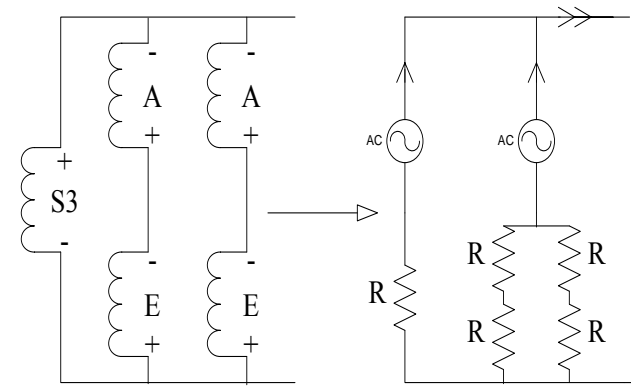

Figure 5. Proposed load-balancing equivalent circuit for each secondary phase

\section{Proposed load-balancing transformer}

Two voltage sources can be paralleled on condition that their amplitudes and phases are identical. Therefore, when three-phase voltages have no zero sequence components, we can reversely add another pair of series windings to each of the secondary-side windings that in turn is paralleled with reverse of two secondary coupling windings in series.

To increase the load compensation, this paper suggests addition of two secondary windings to each phase of original load-balancing transformer.

In this kind of transformer, two-thirds of the load current flow through one winding and the remaining one-third through a set of two series windings. For example, according to Figure 1, twothirds of the load current that is connected to point 3 of the secondary side are supplied by winding Y3 and one-third by the two windings $\mathrm{A}$ and $\mathrm{E}$. Hence, the load current at each phase is not equally supplied from threeprimary phases.

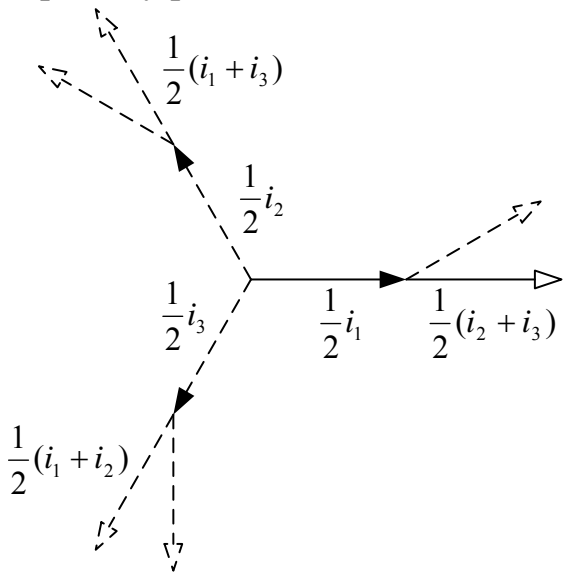

Figure 6. Current distribution in the proposed loadbalancing transformer

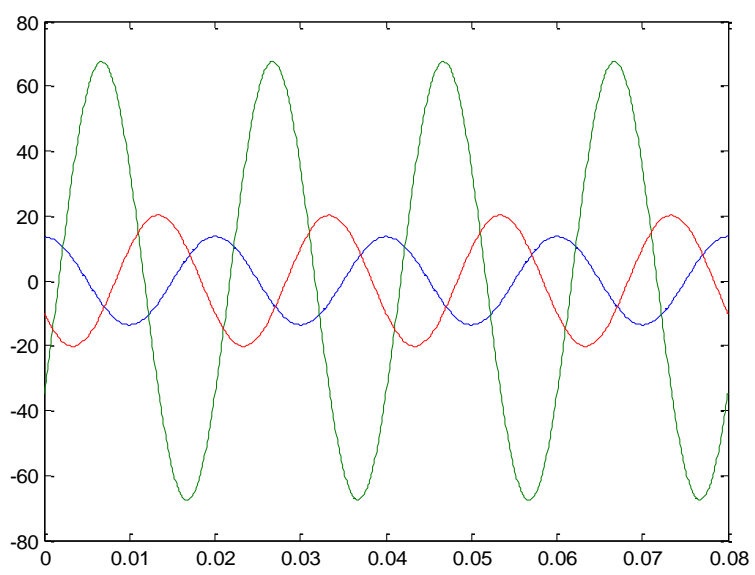

Figure 7. Unbalanced load in secondary side.

The proposed arrangement of connections is shown in Fig. 4. Since the performed parallel connections must have the same phases and amplitudes, thus there is no change in the phase and amplitude of secondary voltage of proposed transformer. Considering connections of Fig. 4, each secondary phase current is provided by parallel branches with the distribution ratio of $1 / 2,1 / 4,1 / 4$. In each phase, two pairs of series windings have been paralleled and the pairs have similar characteristics, namely they have been installed on the same column and their connections are similar. The current flowing through these branches is $1 / 4$ of the load current. Therefore, we can consider equivalent circuit of paralleled windings as Fig. 5. Therefore, the 
supplied current for the load is provided through the primary side phases with the ratio of $1 / 2,1 / 2$ and the optimal condition for the Load-balancing is fulfilled. Fig. 6 illustrates the distribution of secondary side currents over the primary side phases in the proposed transformer.

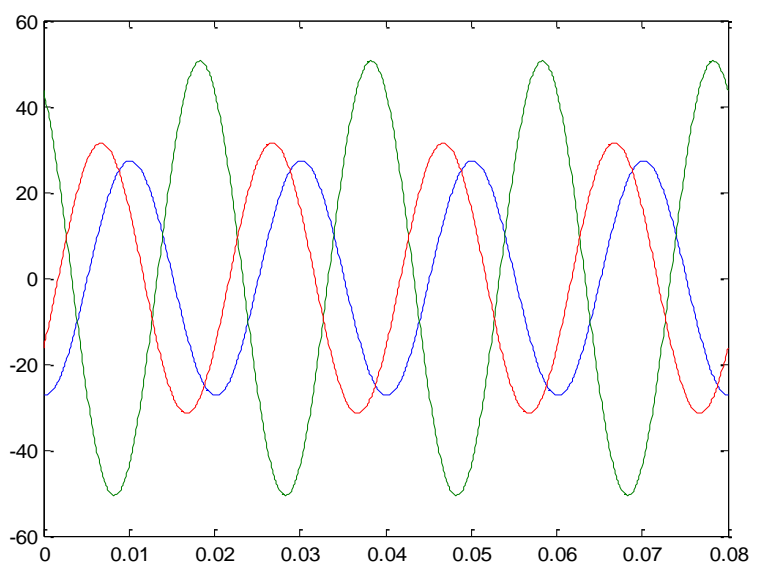

Figure 8. Current in primary side of original loadbalancing transformer

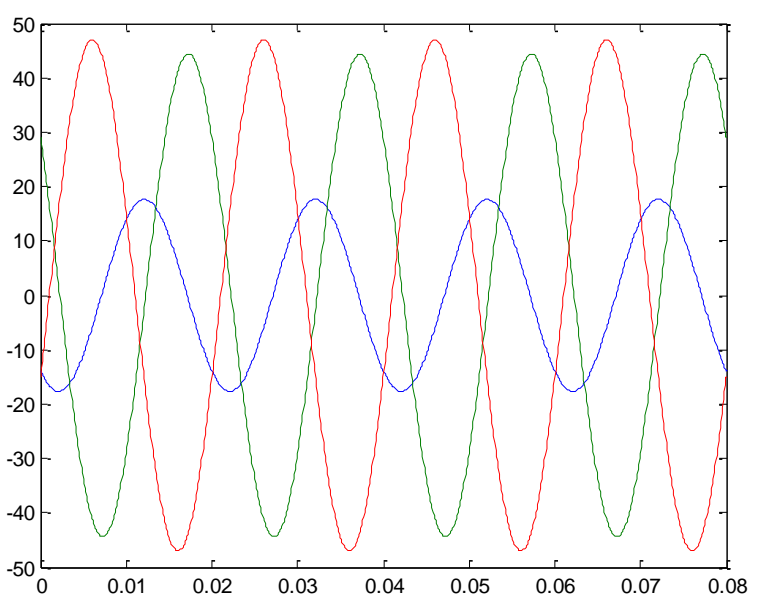

Figure 9. current in primary side of the proposed Loadbalancing transformer

\section{Simulation result}

Assume three single-phase resistive loads $(66 \Omega$, $16.5 \Omega$, and $33 \Omega$ ) are connected to secondary-side phases 1,2 , and 3 . This three-phase load combination consumes purely active power, where no pure reactive compensators are capable of distributing pure active power among the three phases directly. The proposed transformer has been simulated under unbalanced load and compared with the ordinary transformer. Figure 7 shows the unbalanced load currents. In addition, Figs. 8-9 present the three- phase primary currents for the original loadbalancing transformer and the proposed loadbalancing transformer, respectively. It can be seen that in spite of balancing the amplitude, a large amount of phase difference is produced by the original design of the load-balancing transformer. However, the proposed load-balancing transformer is capable of moving towards balancing the unbalanced load both in amplitude and in phase.

\section{Conclusion}

In this paper for balancing of the load in distribution network, a transformer has been proposed which can be simply provided with a little change in the ordinary distribution transformer without any need to the additional special instruments.

A microcontroller can be programmed to select the best possible switching status for balancing purposes. Furthermore, the number of secondary windings is added by introducing a multistage load balancing transformer.

Finally, for improving the performance of this transformer in the Load-balancing, a method has been proposed and simulated using MATLAB and the results have been compared. With respect to low cost of implementation of the proposed idea, and the problems brought in the network by the unbalanced loads, it is recommended to use this transformer instead of the ordinary distribution transformer.

Simulations results show that the proposed transformer can operate in the low voltage system.

\section{References:}

[1] R. Otto, T. Putman, and L. Gyugyi, "Principles and applications of static, thyristor-controlled shunt compensators," IEEE Transactions on Power apparatus and Systems, no. 5, pp. 19351945, 1978.

[2] M. Diab, M. El-Habrouk, T. Abdelhamid, and S. Deghedie, "Survey of active power filters configurations," in 2018 IEEE International Conference on System, Computation, Automation and Networking (ICSCA), 2018: IEEE, pp. 1-14.

[3] Y. Neyshabouri, S. K. Chaudhary, R. Teodorescu, R. Sajadi, and H. Iman-Eini, "Improving the Reactive Current Compensation Capability of Cascaded H-Bridge Based STATCOM under Unbalanced Grid Voltage," IEEE Journal of Emerging and Selected Topics in Power Electronics, 2019. 
[4] S. De and S. Debnath, "Optimal switching strategy of an SVC to improve the power quality in a distribution network," IET Science, Measurement \& Technology, vol. 13, no. 5, pp. 640-649, 2019.

[5] P. S. Georgilakis and N. D. Hatziargyriou, "Unified power flow controllers in smart power systems: models, methods, and future research," IET Smart Grid, vol. 2, no. 1, pp. 2-10, 2019.

[6] M. Nayeripour, E. Mahboubi-Moghaddam, M. R. Narimani, and E. Waffenschmidt, "Secure and Reliable Distribution Feeder Reconfiguration in the Presence of Static VAR Compensator," Iranian Journal of Science and Technology, Transactions of Electrical Engineering, vol. 44, no. 1, pp. 293-308, 2020.

[7] A. Pană, A. Băloi, and F. Molnar-Matei, "New method for calculating the susceptances of a balancing capacitive compensator for a threephase four-wire distribution network," International Journal of Electrical Power \& Energy Systems, vol. 115, p. 105414, 2020.

[8] A. Ram, P. R. Sharma, and R. K. Ahuja, "Adaptive Control Algorithm for DSTATCOM in three phase four wire distribution systems for Power Quality Improvement," in 2019 3rd International Conference on Recent Developments in Control, Automation \& Power Engineering (RDCAPE), 2019: IEEE, pp. 622627.

[9] A. R. Dash, A. K. Panda, R. K. Lenka, and R. Patel, "Performance analysis of a multilevel inverter based shunt active filter with RT-EMD control technique under ideal and non-ideal supply voltage conditions," IET Generation, Transmission \& Distribution, vol. 13, no. 18, pp. 4037-4048, 2019.

[10] S. P. Saini, S. L. Mehta, S. C. Kalra, and P. Dhawan, "Load Balancing Transformer," Water and Energy International, vol. 32, no. 3, pp. 335345, 1975.

[11] B. Ali and I. Siddique, "Distribution system loss reduction by automatic transformer load balancing," in 2017 International Multi-topic Conference (INMIC), 2017, pp. 1-5: IEEE.

[12] M. R. Vuluvala and L. M. Saini, "Load balancing of electrical power distribution system: An overview," in 2018 International Conference on Power, Instrumentation, Control and Computing (PICC), 2018, pp. 1-5: IEEE.

[13] A. ORLOV, S. VOLKOV, A. SAVELYEV, I. GARIPOV, and A. OSTASHENKOV, "Losses in three-phase transformers at load balancing," Revista ESPACIOS, vol. 38, no. 52, 2017.

[14] H. Zhao, Q. Wu, J. Wang, Z. Liu, M. Shahidehpour, and Y. Xue, "Combined active and reactive power control of wind farms based on model predictive control," IEEE Transactions on Energy Conversion, vol. 32, no. 3, pp. 1177-1187, 2017.

[15] L. L. Grigsby, Power system stability and control. CRC press, 2016.

[16] F. M. Camilo, R. Castro, M. Almeida, and V. F. Pires, "Probabilistic load elasticity analysis in low voltage distribution networks with high penetration of photovoltaic micro generation," International Journal of Electrical Power \& Energy Systems, vol. 113, pp. 782791, 2019.

[17] G. Gruosso, R. S. Netto, L. Daniel, and P. Maffezzoni, "Joined Probabilistic Load Flow and Sensitivity Analysis of Distribution Networks Based on Polynomial Chaos Method," IEEE Transactions on Power Systems, vol. 35, no. 1, pp. 618-627, 2019.

[18] D. Schwanz, F. Möller, S. K. Rönnberg, J. Meyer, and M. H. Bollen, "Stochastic assessment of voltage unbalance due to singlephase-connected solar power," IEEE Transactions on Power Delivery, vol. 32, no. 2, pp. 852-861, 2016.

[19] A. M. El-Refaie, "Motors/generators for traction/propulsion applications: A review," IEEE Vehicular Technology Magazine, vol. 8, no. 1, pp. 90-99, 2013.

[20] M. Jafari, Z. Malekjamshidi, and J. Zhu, "Design and development of a multi-winding high-frequency magnetic link for grid integration of residential renewable energy systems," Applied energy, vol. 242, pp. 12091225, 2019.

[21] J. Mikulović, B. Škrbić, and Ž. Đurišić, "Power definitions for polyphase systems based on Fortescue's symmetrical components," International Journal of Electrical Power \& Energy Systems, vol. 98, pp. 455-462, 2018

\section{Creative Commons Attribution License 4.0 (Attribution 4.0 International, CC BY 4.0)}

This article is published under the terms of the Creative Commons Attribution License 4.0

https://creativecommons.org/licenses/by/4.0/deed.en_US 